\title{
COMPETENCY-BASED EDUCATION MANAGEMENT
}

\author{
DR. PAVAN KUMAR SHARMA ${ }^{1}$, OMPRAKASH SWAMI ${ }^{2}$, HEMANT TYAGI ${ }^{3}$ \\ ${ }^{1}$ Vice Principal, Jaipur Hospital College of Nursing, Jaipur \\ ${ }^{2}$ Asso. Prof., Mahatma Gandhi Nursing College, Sitapura, Jaipur \\ ${ }^{2}$ Principal, Imperial College of Nursing, Jaipur \\ Corresponding email: koshikpavan@gmail.com
}

\begin{abstract}
Competency-based education is design to develop and put force to desired performance by the health care professionals. CBE is a traditional framework and it help the person for establishing in measurable criterion that learner want to complete. By this method through $\mathrm{CBE}$ individual perform the task according to established expectation which is medical professionals is consider too competent.
\end{abstract}

Keyword: Competency, Education, Management

Complimentary education and its goal develop from traditional education and its frameworks have been on learning outcomes or objectives. "Competency based education and its main use is good communication, knowledge, skill, clinical development and emotions in the regular use for the benefit of individual and all the community people. This includes in all results of educational system or process. This is well known that all result occurs due to regular practice and use. Result never occurs without practices or focusing.

\section{A competency focuses on the performance of the end-product or goal-state of instruction}

Main focus of education on hoe learner are taught and getting less so on whether or not individual can understand to problem solving process, able to perform procedure, communicate effectively, able to take good decision. CBE is not focus on just result but it also focus on significant result, even dramatic shift in what educators and policy-makers look for in judging the effectiveness of educational programs. To know the learner outcomes of "knows" and "knows how" may be sufficient but in the developed of highly advance learner goals for educational activities to high at level of shows and does.

In CBE, main issue is the learner will able to find out the proper places or performance according to competence or not. In the CBE learner try to identified how they can reach the goal point
2. A competency reflects expectations that are external to the immediate instructional program

Traditional educational programs too often have an insular character in which the expectations of learners are based on what has been taught with internal, educational metrics of success such as performance on a standardized exam. In the Competency based education learner success is identified by his capacity to perform which are determined by stakeholder outside the educational institute.

3. A competency is expressible in terms of measurable behavior

By the traditional education it does not assess learner knowledge level and its developments CBE include a much higher premium on learner performance of tasks and activities representative of the competencies. These types of assessment process are just a paper and pencil test for assessing the knowledge. CBE more focus on behavioral measure that required knowledge and skill which is educational experiences and study in his part of curriculum.

4. A competency based standard for evaluating competence that is not dependent upon the different learner performance

All performance must be assessed according to competence and by given criterion for identification or evaluated that learner received proper required level of 
performance or not as per given competency level. These criteria or performance standards are not determined by the performance of other learners (i.e., not graded on a ,curve ${ }^{\text {ee }}$ ) but by the expert judgment of practitioners and educators in the field. This it is important that all the learner in the medical field should achieve competence level after the training programme.

\section{A competency informs learners, as well as other stakeholders, about what is expected of them}

Put the more attention on the outcomes of education based on CBE because it is more transparent and accountable to learners. Indeed, defining a discipline's values, goals and priorities is an implicit part of defining competencies, which enables the competencies to communicate these values and expectations to various stakeholders within and outside the discipline.

\section{Defining the curriculum for competency-based education}

Curriculum for a learner is the heart of any educational model or system. Curriculum developed from the different traditional models from CB.

In the past history the professions themselves develop a requirement which serve to determine who can obtain membership based on completion of curriculum that they determine. While often positioning them to serve the public good, there is also a tendency to serve the needs of their own professions and members. in general curriculum become tie up to historical gift that set out the tradition, priorities and values of the faculty in medical profession.

According to time the curricula can be modified by the replacing of new or current information. It is hard with less attention to the remove of the elements that are found to be less reasonable to current practice. Generally it is the scope of scientific new knowledge that coming from the curriculum, at the scope focus on the implementation of what is already known to be benefitted.
The practical steps in implementing a competencybased educational system

In the last five years it has been seen that development of competencies in different health professional fields now a days in an increased manner, including medicine, nursing, midwifery, and public health. Many organizations take initiation to start to provide expected knowledge, skills and behaviors of graduate practitioners as per current situation. For developing the important contribution, many fall short of a fully developed CBE model because it focus on a learning objectives.

Common pitfalls to the development of $\mathrm{CBE}$ given below

- Fail to getting proper address the health related requirements of community.

- Competencies are not adequately define

- A lack of accommodation in the curriculum for the flexibility in learning rates and the lack of assessment methods to determine when competency has been achieved.

CONCLUSION: Appraisal of any performance of an individual provide to chance to improve his performance as according to goal of organization.

\section{REFERENCE:}

1. Epstein RM. Assessment in medical education. New England Journal of Medicine. 2007; 356:38796.

2. Long DM. Competency-based residency training: the next advance in graduate medical education. Acad Med. 2000 2000;75:1175-83.

3. Huddle TS, Heudebert GR. Taking apart the art: the risk of anatomizing clinical competence. Acad Med. 2007 Jun;82(6):536-41.

4. McMahon GT, Tallia AF. Anticipating the Challenges of Reforming the United States Medical Licensing Examination. Acad Med. 2010;85:453-6.

5. Norcini JJ. Current perspectives in assessment: the assessment of performance at work. Medical Education. 2015;39:880-9. 